\title{
Cerrahlardaki egzersiz alışkanlığının kas-iskelet sistemi ağrısına ve postüre etkisi
}

\author{
The effect of exercise habits in surgeons on musculoskeletal pain and posture
}

\author{
Sefa Alperen Öztürk, Görkem Kıyak, Esma Arslan, Hüseyin Tolga Acar, Sabriye Ercan, Cem Çetin
}

Gönderilme tarihi:27.09.2021

Kabul tarihi:20.10.2021

Öz

Amaç: Düzenli egzersiz yapma alışkanlığı olan ve olmayan cerrahların, kas-iskelet sistemi ağrıları ve postürleri arasındaki farkın belirlenmesidir.

Gereç ve yöntem: Hastanemizde en az bir yıldır çalışan ve benzer ergonomik risklere sahip olan cerrahlar düzenli egzersiz yapma alışkanlıklarının olup olmamasına göre iki gruba ayrılmıştır. Katılımcıların; tanımlayıcı bilgi formu, Örebro kas-iskelet ağrı tarama anketi (ÖKİA), New York postür derecelendirmesi ve İşyeri Ergonomik Risk Değerlendirmesi yüz yüze ortamda yapılmıştır.

Bulgular: Çalışmaya, \%78,9 ( $n=45)^{\prime}$ 'u erkek ve \%21,1 $(n=12)$ 'i kadın cerrah dahil edildi. Cerrahların $\% 10,5$ $(n=6)$ 'i, meslek hayatları boyunca işleri ile ilgili sağılı sorunu/yaralanma geçirdiklerini bildirdi. Cerrahların \%7 $(n=4)$ 'sinin düşük, \%89,5 (n=51)'inin orta ve \%3,5 (n=2)'inin yüksek düzeyde ergonomik riske sahip olduğu saptandı. Çalışmaya katılan tüm cerrahların, çok iyi düzeyde postüre sahip oldukları belirlendi. Egzersiz yapma alışkanlığı olan cerrahların $(n=21)$ vücut kütle indeksinin daha düşük $(p=0,018)$ ve postürünün daha düzgün olduğu tespit edildi $(p=0,023)$. Düzenli egzersiz yapmayan cerrahların ÖKİA puanı daha yüksek olmakla birlikte istatistiksel anlamlı fark belirlenmedi $(p>0,05)$. ÖKİA puanının New York postür derecelendirmesi puanı ile negatif yönlü; New York postür derecelendirmesinin ise vücut kütle indeksi ile negatif yönlü, egzersiz süresi ve egzersiz yılı ile pozitif yönlü doğrusal ilişki gösterdiği tespit edildi $(p<0,05)$.

Sonuç: Çalışmaya katılan cerrahların çoğunluğunun orta düzeyde ergonomik riske, tamamının ise çok iyi düzeyde postüre sahip olduğu tespit edildi. Egzersiz yapma alışkanlığının cerrahların vücut kütle indeksi, iş kaynaklı kas-iskelet sistemi ağrısı düzeyi ve postür düzgünlüğüne olumlu etkisi olduğu belirlendi.

Anahtar kelimeler: Cerrah, egzersiz, ağrı, postür.

Öztürk SA, Kıyak G, Arslan E, Acar HT, Ercan S, Çetin C. Cerrahlardaki egzersiz alışkanlığının kas-iskelet sistemi ağrısına ve postüre etkisi. Pam Tıp Derg 2022;15:117-123.

\begin{abstract}
Purpose: To determine the difference between musculoskeletal pain and postures of surgeons who do/do not exercise regularly.

Materials and methods: Surgeons who have been working in our hospital for at least one year and have similar ergonomic risks were divided into two groups according to whether they have regular exercise habits or not. Descriptive information form, Orebro musculoskeletal pain screening questionnaire (OMPQ), New York posture rating, and workplace ergonomic risk assessment were conducted in a face-to-face setting with participants.

Results: The study included $78.9 \%(n=45)$ male and $21.1 \%(n=12)$ female surgeons. $10.5 \%(n=6)$ of surgeons reported having a work-related health problem or injury during their professional life. It was determined that $7 \%$ $(n=4)$ of the surgeons had low, $89.5 \%(n=51)$ moderate and $3.5 \%(n=2)$ high-level ergonomic risk. All surgeons that participating in the study had an excellent posture. Surgeons who exercised regularly $(n=21)$ had a lower body mass index $(p=0.018)$ and a more straight posture $(p=0.023)$. Although the OMPQ score was higher in surgeons who did not exercise regularly, no statistically significant difference was found $(p>0.05)$. The OMPQ score was negatively correlated with the New York posture rating score. However, the New York posture rating showed a negative linear relationship with body mass index and a positive linear relationship with exercise duration and total exercise time $(p<0.05)$.
\end{abstract}

Conclusion: The majority of the surgeons in the study were found to have a moderate level of ergonomic risk,

\footnotetext{
Sefa Alperen Öztürk, Dr. Öğr. Üye. Süleyman Demirel Üniversitesi Tıp Fakültesi Üroloji Anabilim Dalı, Isparta, Türkiye, e-posta: dr.sefa.alperen@ gmail.com (https://orcid.org/0000-0003-4586-9298) (Sorumlu Yazar)

Görkem Kıyak, Asistan Dr. Süleyman Demirel Üniversitesi Tıp Fakültesi Spor Hekimliği Anabilim Dalı, Isparta, Türkiye, e-posta: gorkemkiyak0@ gmail.com (https://orcid.org/0000-0003-4780-8480)

Esma Arslan, Asistan Dr. Adres: Süleyman Demirel Üniversitesi Tıp Fakültesi Spor Hekimliği Anabilim Dalı, Isparta, Türkiye, e-posta: esmaarslan. sdu@gmail.com (https://orcid.org/0000-0001-7097-8619)

Hüseyin Tolga Acar, Asistan Dr. Süleyman Demirel Üniversitesi Tıp Fakültesi Spor Hekimliği Anabilim Dalı, Isparta, Türkiye, e-posta: md.tolgaacar@gmail.com (https://orcid.org/0000-0003-4970-9929)

Sabriye Ercan, Doç. Dr. Süleyman Demirel Üniversitesi Tıp Fakültesi Spor Hekimliği Anabilim Dalı, Isparta, Türkiye, e-posta: sabriyeercan@ gmail.com (https://orcid.org/0000-0001-9500-698X)

Cem Çetin, Prof. Dr. Süleyman Demirel Üniversitesi Tıp Fakültesi Spor Hekimliği Anabilim Dalı, Isparta, Türkiye, e-posta: sporhekimi@gmail. com (https://orcid.org/0000-0002-8151-9554)
} 
and all of them had excellent posture. The habit of exercising positively impacted the surgeons' body mass index, work-related musculoskeletal pain level, and posture.

Key words: Surgeon, exercise, pain, posture.

Ozturk SA, Kiyak G, Arslan E, Acar HT, Ercan S, Cetin C. The effect of exercise habits in surgeons on musculoskeletal pain and posture. Pam Med J 2022;15:117-123.

\section{Giriş}

Kas ve iskelet sistemi ağrıları, Avrupa'da en yaygın görülen meslek hastalığı olarak bildirilmiştir [1-3]. Bir meslek hastalığı olarak kasiskelet sistemi ağrısı; uzun ve monoton çalışma saatleri ve yanlış postür gibi risk faktörleri olan mesleklerde daha sık görülmektedir [4]. Cerrahlar da diğer sağlık profesyonelleriyle birlikte bu risklerin yüksek olduğu meslek grubundadır [1]. Ameliyat sırasında tekrarlayan zorlayıcı hareketlerin yer aldığı eforlu bir çalışma ortamı sonucunda yanlış postür kaçınılmaz hale gelir. Ayrıca, ameliyat masasında sabit bir postüre sahip olan cerrahlar; kolları gövdeden ileriye uzanmış ve boyunları öne eğilmiş bir biçimde çalışmaya meyillidir. Bu durum omuzboyun bölgesine aşırı yük bindirir [5]. İnce ve hassas hareket gerektiren cerrahi teknikler, uzun süreli bel stabilizasyonu ile birlikte kolların ve ellerin yanlış postürüne sebep olabilir [5]. Bu yanlış postür ve yetersiz ergonomik çalışma ortamı, cerrahlarda görülen kas-iskelet sistemi ağrıları için öne sürülen en önemli etyolojik faktörlerdir [6].

Uygunsuz postür ve bu duruma ikincil olarak gelişebilen kas-iskelet sistemi ağrıları, cerrahların iş gücünü olumsuz yönde etkiler [7]. Günümüzde tıp eğitimi uzun ve yorucu bir süreçtir. Bir cerrahın yetişmesi için gerekli olan emek ve maliyet yadsınamazken bu yetişmiş bireylerin sağlıklarını koruması hem kendileri hem de hastaları için değer taşır. Aynı şekilde kas-iskelet sistemi ağrıları ve kronik yorgunluk cerrahın sosyo-psikolojik sağlığını etkilemekte hatta sosyal hayattan soyutlayabilmektedir [7]. Uzun çalışma saatleri sonucunda yorulmuş bir beden ve zihinle sosyal hayata adaptasyon zorlaşır [8]. Düzenli egzersiz yapan bir cerrah için ise bu durum hem yeni bir sosyal çevre oluşturma hem de psikolojik olarak kendini sağlıklı hissetme açısından önemlidir [8]. Oysa çoğu cerrah mesai saatleri dışındayken kasiskelet sistemi ağrılarını işinin bir gerekliliği gibi görmekte ve sedatif bir dinlenme periyoduyla bir sonraki iş gününü beklemektedir [9].
Literatür tarandığında, sağlık çalışanlarında kas-iskelet sistemi rahatsızlıkları ile ilgili çalışmalar sıklıkla heterojen bir grup olarak tüm sağlık profesyonellerini içermektedir [7, 10]. Cerrahlar üzerinde yapılan çalışmalar incelendiğinde ise bu çalışmaların cerrahların kas-iskelet sistemi ağrıları, postürleri ve ergonomileri üzerine odaklandığı görülmektedir $[1,2,7]$. Egzersiz yapma alışkanlığının, cerrahlardaki kas-iskelet sistemi kaynaklı ağrılarına veya postüre etkisini incelmeye yönelik yeterli çalışma bulunmamaktadır.

$\mathrm{Bu}$ çalışmanın hipotezi; düzenli egzersiz yapma alışkanlığı olan cerrahların kas-iskelet sistemi yakınmasının daha az ve postürlerinin daha düzgün olacağıdır. Hipotezi test etmek için bu çalışmada, düzenli egzersiz yapma alışkanlığı olan ve olmayan cerrahların kasiskelet sistemi ağrıları ve postürleri arasında farkın belirlenmesi amaçlanmıştır.

\section{Gereç ve yöntem}

Araştırma, Süleyman Demirel Üniversitesi Tıp Fakültesi Klinik Araştırmalar Etik Kurulu Başkanlığı tarafından onaylanmıştır. Çalışmanın evrenini; hastanemizde en az bir yıldır cerrahi bilim kliniklerinde hekim olarak çalışan bireyler oluşturmuştur.

Hastanemizin temel bilim ve dahili bilim kliniklerinde hekim olanlar, bir yıldan daha az süredir cerrahi bilim kliniklerinde hekim olarak çalışanlar ve bilinen inflamatuvar kas-iskelet sistemi hastalığı olanlar çalışmaya alınmadı.

Katıımcıların; tanımlayıcı bilgi formu, Örebro kas-iskelet ağrı tarama anketi, New York postür derecelendirmesi ve İşyeri Ergonomik Risk Değerlendirmesi yüz yüze ortamda yapıldı. Kullanılan ölçme-değerlendirme araçlarının kullanımı için gerekli etik kurallara dikkat edildi.

Örebro kas-iskelet ağrı tarama anketi (ÖKIA): Türkçe geçerliği ve güvenilirliği Öncü ve ark. [11] tarafından sağlanan bu anket, demografik (4 soru) ve ağrı ile ilişkili durumu 
(21 soru) sorgulayan toplam 25 sorudan oluşur. Anketten alınan puan, 0 ile 210 puan arasında değişmektedir. Puanın artması, kas-iskelet sistemi ilişkili ağıı yakınmasının arttığı anlamına gelir.

New York postür derecelendirmesi (NYPD): $\mathrm{Bu}$ derecelendirmede, vücudun 13 farklı kısmında oluşabilecek postüral değişiklikler izlenerek puanlama yapılır. İncelenen kısımdaki postüral yapı düzgün ise 5 puan, orta derecede bozukluk varsa 3 puan, ciddi derecede bozukluk gözleniyorsa 1 puan verilir. Değerlendirmenin sonunda skaladan 13 ile 65 puan arasında bir puan alınır. Sonuç puanının 45 puan ve üstünde olması 'çok iyi', 40-44 puan aralığında olması 'iyi', 30-39 puan aralığında olması 'orta', 20-29 puan aralığında olması 'zayıf', 19 puan ve altında olması ise 'kötü' postür olarak sınıflandırılır [12].

İşyeri Ergonomik Risk Değerlendirmesi (IERD): Bu değerlendirme, iş ile ilişkili kasiskelet sistemi bozukluklarını taramayı amaçlar. $\mathrm{Bu}$ araçta; omuz, bilek, sırt, boyun ve bacak bölgelerinin maruz kaldığı 6 farklı (duruş, tekrarlama, kuvvet, titreşim, temas stresi ve görev süresi) risk değerlendirilmektedir. Değerlendirmenin sonunda 8-27 aralığında puan alınması iş yerindeki ergonomik riskin 'düşük', 28-44 aralığında puan alınması 'orta' ve 45-54 aralığında puan alınması 'yüksek' olduğu anlamına gelir [13].

\section{İstatistiksel analiz}

Verilerin değerlendirilmesinde SPSS v.23 paket programı kullanıldı. Verilerin homojen dağılımı sağlayıp sağlamadığı Shapiro Wilk testi ile incelendikten sonra gruplar arasındaki fark bağımsız gruplarda t testi ile analiz edildi. Değişkenler arasındaki ilişki Pearson korelasyon analizi ile test edildi. $p$ değeri 0,05 düzeyinde anlamlı kabul edildi. Veriler; sıklık, yüzde oranı ve ortalama \pm standart sapma olarak sunuldu.

\section{Bulgular}

Çalışmaya, \%78,9 (n=45)'u erkek ve \%21,1 (n=12)'i kadın olmak üzere cerrahi bilim kliniklerinde görev yapan 57 araştırma görevlisi doktor dahil edildi. Katılımcıların \%3,5 ( $n=2$; 1 cerrah: hipertansiyon, 1 cerrah: polikistik over sendromu)'i bilinen bir hastalığının olduğunu beyan etti. Cerrahların \%10,5 $(n=6)$ 'i, meslek hayatları boyunca işleri ile ilgili sağlık sorunu/yaralanma geçirdiklerini bildirdi. İşyeri Ergonomik Risk Değerlendirmesi'ne göre cerrahların $\% 7(n=4)$ 'sinin düşük, $\% 89,5$ $(n=51)$ 'inin orta ve \%3,5 (n=2)'inin yüksek düzeyde ergonomik riske sahip olduğu saptandı. Çalışmaya katılan tüm cerrahların, New York postür derecelendirmesinden 45 üstünde puan alarak çok iyi düzeyde postüre sahip oldukları belirlendi.

Haftada en az 90 dakika düzenli egzersiz yapma alışkanlığı olan cerrahların oranı \%36,8 $(n=21)$ olarak hesaplandı. Egzersiz yapma alışkanlığı olan cerrahların (Grup egzersiz, n=21) haftalık egzersiz süresi $140,7 \pm 43,6$ dakika ve egzersize devamlılıkları 4,7 $\pm 3,3$ yıl olarak ölçüldü. Düzenli egzersiz yapma alışkanlığı olan cerrahların vücut kütle indeksinin(VKI) daha düşük ( $p=0,018$, Tablo 1$)$ ve postürünün daha iyi düzeyde olduğu tespit edildi ( $p=0,023$, Tablo 2). Düzenli egzersiz yapmayan cerrahların ÖKIA tarama anketi puanı daha yüksek olmakla birlikte istatistiksel anlamlı fark saptanmadı ( $p>0,05$, Tablo 2).

Tablo 1. Cerrahların tanımlayıcı özellikleri

\begin{tabular}{lllll}
\hline & Tümü $(\mathrm{n}=57)$ & $\begin{array}{l}\text { Grup sedanter } \\
(\mathrm{n}=36)\end{array}$ & $\begin{array}{l}\text { Grup egzersiz } \\
(\mathrm{n}=21)\end{array}$ & $p$ değeri \\
\hline Yaş (yıl) & $29,4 \pm 2,7$ & $29,5 \pm 3,1$ & $29,2 \pm 2,0$ & 0,927 \\
Vücut Kütle İndeksi (kg/m²) & $25,4 \pm 2,8$ & $26,1 \pm 2,7$ & $24,3 \pm 2,5$ & $\mathbf{0 , 0 1 8 ^ { * }}$ \\
Mesleki deneyim süresi (yıl) & $4,9 \pm 2,7$ & $5,1 \pm 3,1$ & $4,5 \pm 1,8$ & 0,881 \\
Cerrahi bilim kliniklerinde çalışma süresi (yıl) & $2,7 \pm 1,3$ & $2,8 \pm 1,3$ & $2,6 \pm 1,2$ & 0,634 \\
Toplam çalışma süresi (saat/hafta) & $82,3 \pm 23,4$ & $80,5 \pm 24,3$ & $85,4 \pm 22,1$ & 0,589 \\
Cerrahi operasyon yapma süresi (saat/hafta) & $26,6 \pm 10,1$ & $27,5 \pm 10,7$ & $25,0 \pm 9,1$ & 0,470 \\
Uyku süresi (saat/gün) & $5,4 \pm 0,9$ & $5,3 \pm 1,0$ & $5,4 \pm 0,8$ & 0,695 \\
\hline
\end{tabular}

*: $p$ değeri 0,05 düzeyinde istatistiksel anlamlıdır 
Tablo 2. Cerrahların kas-iskelet sistemi ağrısı, postürü ve ergonomik risk düzeyi

\begin{tabular}{lllll}
\hline & Tümü $(\mathrm{n}=57)$ & $\begin{array}{l}\text { Grup sedanter } \\
(\mathrm{n}=36)\end{array}$ & $\begin{array}{l}\text { Grup egzersiz } \\
(\mathrm{n}=21)\end{array}$ & $p$ değeri \\
\hline ÖKIA & $81,8 \pm 26,9$ & $84,9 \pm 22,4$ & $76,3 \pm 33,1$ & 0,295 \\
NYPD & $56,1 \pm 4,6$ & $55,1 \pm 4,2$ & $57,9 \pm 4,8$ & $\mathbf{0 , 0 2 3 ^ { * }}$ \\
$\begin{array}{l}\text { IERD puanı } \\
\text { IERD sınıflandırma (n (\%)) }\end{array}$ & $36,6 \pm 5,0$ & $36,7 \pm 4,7$ & $36,3 \pm 5,6$ & 0,967 \\
$\quad$ & & & 0,116 \\
$\quad$ Düşük & $4(7)$ & $1(2,8)$ & $3(14,3)$ & \\
$\quad$ Orta & $51(89,5)$ & $33(91,6)$ & $18(85,7)$ & \\
$\quad$ Yüksek & $2(3,5)$ & $2(5,6)$ & $0(0)$ & \\
\hline
\end{tabular}

*: $p$ değeri 0,05 düzeyinde istatistiksel anlamlıdır

ÖKIA: Örebro kas-iskelet ağrı tarama anketi

NYPD: New York postür derecelendirmesi

IERD: İşyeri Ergonomik Risk Değerlendirmesi

Yapılan korelasyon analizi sonucunda, ÖKİA puanının NYPD puanı ile negatif yönlü doğrusal ilişkisi belirlendi. NYPD'nin ise VKI ve ÖKIA puanı ile negatif yönlü, egzersiz süresi (dk/hf) ve egzersiz yılı ile pozitif yönlü doğrusal ilişki gösterdiği bulundu (Tablo 3).

Tablo 3. Değişkenlerin Örebro kas-iskelet ağrı tarama anketi ve New York postür derecelendirmesi ile ilişkisi

\begin{tabular}{|c|c|c|c|}
\hline & & ÖKİA & NYPD \\
\hline \multirow[t]{2}{*}{ Yaş (yıl) } & $r$ & 0,156 & $-0,075$ \\
\hline & $p$ & 0,248 & 0,577 \\
\hline \multirow[t]{2}{*}{ Vücut Kütle İndeksi (kg/m²) } & $r$ & 0,010 & $-0,554^{* *}$ \\
\hline & $p$ & 0,942 & 0,0001 \\
\hline \multirow[t]{2}{*}{ Mesleki deneyim süresi (yıl) } & r & 0,241 & $-0,133$ \\
\hline & $p$ & 0,071 & 0,323 \\
\hline \multirow[t]{2}{*}{ Cerrahi bilim kliniklerinde çalışma süresi (yıl) } & r & 0,074 & $-0,179$ \\
\hline & $p$ & 0,586 & 0,184 \\
\hline \multirow[t]{2}{*}{ Toplam çalışma süresi (saat/hf) } & $r$ & $-0,153$ & 0,137 \\
\hline & $p$ & 0,257 & 0,309 \\
\hline \multirow[t]{2}{*}{ Cerrahi operasyon yapma süresi (saat/hafta) } & $r$ & 0,012 & 0,057 \\
\hline & $p$ & 0,932 & 0,674 \\
\hline \multirow[t]{2}{*}{ Uyku süresi (saat/gün) } & r & $-0,182$ & $-0,159$ \\
\hline & $p$ & 0,177 & 0,238 \\
\hline \multirow[t]{2}{*}{ ÖKİA } & $r$ & 1 & $-0,296^{*}$ \\
\hline & $p$ & - & 0,025 \\
\hline \multirow[t]{2}{*}{ NYPD } & r & $-0,296^{*}$ & 1 \\
\hline & $p$ & 0,025 & - \\
\hline \multirow[t]{2}{*}{ İERD puanı } & r & 0,136 & 0,058 \\
\hline & $p$ & 0,314 & 0,667 \\
\hline \multirow[t]{2}{*}{ Egzersiz süresi (dk/hf) } & $r$ & $-0,156$ & $0,313^{*}$ \\
\hline & $p$ & 0,248 & 0,018 \\
\hline \multirow[t]{2}{*}{ Egzersiz yılı } & r & $-0,183$ & $0,340 *$ \\
\hline & $p$ & 0,174 & 0,010 \\
\hline
\end{tabular}

*: $p$ değeri 0.05 düzeyinde istatistiksel anlamlıdır, **: $p$ değeri 0.01 düzeyinde istatistiksel anlamlıdır r: 0,2-0,4 iken zayıf düzeyde, r: 0,4-0,6 iken orta düzeyde ilişki göstermiştir

ÖKIA: Örebro kas-iskelet ağrı tarama anketi

NYPD: New York postür derecelendirmesi

IERD: İşyeri Ergonomik Risk Değerlendirmesi 


\section{Tartışma}

Çalışmamızın evrenini oluşturan cerrahların büyük bir kısmının orta düzeyde ergonomik riske sahip olduğu, tamamının ise çok iyi düzeyde postüre sahip olduğu tespit edilmiştir. Öte yandan, egzersiz yapma alışkanlığının cerrahların vücut kütle indeksine, iş kaynaklı kasiskelet sistemi ağrısı düzeyine ve postürlerinin düzgünlüğüne olumlu etkiler oluşturduğu belirlenmiştir.

Önceki çalışmalarda, cerrahi yöntem ve/ veya cerrahi disiplinler ergonomik risk açısından karşılaştırımıştır. Catanzarite ve ark.'nın [14] yaptığı derlemede açık cerrahi, laparoskopik cerrahi, vajinal cerrahi ve robotik cerrahi gibi farklı tekniklerde ergonomik risk faktörleri farklı olmasına karşın ergonomik risk oranları yüksek bulunmuştur. Benzer bir çalışmada, giyilebilir teknoloji ürünleri kullanılarak operasyonlar sırasındaki ergonomik risk değerlendirilmiş ve cerrahların \%65'inin yanlış boyun postüründen kaynaklı yüksek düzeyde ergonomik riske sahip oldukları bildirilmiştir [15]. Bu çalışmalarla karşılaştırıldığında çalışmamıza katılan cerrahların \%89,5'inin ergonomik risk düzeyi 'orta' olarak belirlenmiştir. Literatürdeki diğer çalışmalarda cerrahların risk düzeyi 'yüksek' olarak raporlanırken çalışmamızda sıklıkla 'orta' risk düzeyinin tespit edilmiş olması ergonomik riskleri değerlendirilme yönteminin çalışmalara göre farklılık göstermesi ve diğer çalışmalarda spesifik cerrahi modaliteler üzerine odaklanılmış olmasıdır. Aynı zamanda, çalışmamızın evrenini daha genç cerrahların oluşturması ergonomik riskin orta, postürün ise çok iyi çıkmasının nedeni olabileceğini düşündürmektedir. Ancak literatür tarandığında genç cerrahların tecrübesizliklerinden kaynaklı olarak ergonomik risklerinin daha fazla olduğunu savunan çalışmalar olduğu da görülmektedir [7]. Cerrahların tecrübe düzeylerine göre sınıflandırılarak tasarlanacak yeni çalışmalarda, bu ayrımın daha doğru saptanabileceği düşünülmektedir.

Meltzer ve ark.'nın [15] çalışmasında cerrahlar için en yüksek postural boyun riskinin açık ve laparoskopik cerrahi sırasında oluştuğu belirlenmiştir. Ancak bu çalışmada daha çok uygunsuz postürün ergonomik bir risk faktörü olduğu savunulmuş ve genel postür değerlendirilmesi yapılmamıştır. Literatür tarandığında genellikle çalışmaların postüral risk üzerinde durduğu ve genel bir postür değerlendirilmesi yapılan çalışma eksikliği olduğu göze çarpmaktadır $[1,2,7]$. Bizim çalışmamızda ise cerrahların postürlerinin çok iyi düzeyde olduğu belirlenmiştir. Diğer taraftan, düzenli egzersiz yapan cerrahların postürlerinin anlamlı düzeyde daha düzgün olduğu, postürün kas-iskelet sistemi ağrıları ile negatif yönlü ilişki gösterdiği saptanmıştır. Bu bağlamda, iş kaynaklı postüral olumsuz etkilenme ve kas-iskelet sistemi ağrıları ile karşılaşma riski bulunan cerrahların düzenli egzersiz yapması ideal postürlerini korumalarına ve daha az ağrı hissetmelerine katkı sağlayacaktır.

Düzenli egzersiz yapmanın vücut ağırlığını dolayısıyla VKI'ni düşürdüğü bilinen bir gerçektir [16-18]. Çalışmamızda düzenli egzersiz yapan cerrahların düzenli egzersiz yapmayan cerrahlara kıyasla VKl'si daha düşük ve ve postürleri daha iyi olarak saptanmıştır.

Bu çalışmada, düzenli egzersiz yapmayan cerrahların düzenli egzersiz yapan cerrahlara göre ÖKİA puanı daha yüksek olmakla beraber istatistiksel anlamlı fark belirlenmemiştir. Önceki çalışmalar, cerrahların yüksek (\%73-\%88) oranda kas-iskelet sistemi ağrısı şikayetleri bildirdiğini vurgulamaktadır [3]. Literatürde cerrahlar üzerine odaklanmış bir çalışma olmamakla birlikte düzenli egzersiz yapmanın kas-iskelet sistemi ağrılarını azalttığı yönünde ortak sonuca varmış yayınlar bulunmaktadır [1921]. Cerrahların diğer sağlık çalışanlarına göre daha ağır fiziksel ve zihinsel tempoda çalışması postüral sorunlarla beraber kas-iskelet sistemi ağrılarını arttırmaktadır [7]. Düzenli egzersiz yapmanın hem postür sorunlarını azaltarak dolaylı hem de doğrudan kas-iskelet sistemi şikayetlerini azalttığı düşünülmektedir [22, 23]. Çalışmamızda da bu sav desteklenmektedir.

Egzersiz süresi/yılı artııça ve VKİ değerleri düştükçe postür skorunun arttığının gösterildiği çalışmamızda, ÖKIA puanı yükseldikçe postür skoru azalmıştır. Düzenli egzersiz yapmak cerrahların VKİ değerini düşürmekte, dolayısıyla cerrahlar daha iyi bir postüre sahip olmakta ve cerrahların kas-iskelet sistemi şikayetleri azalmaktadır. Asghari ve ark.'nın [10] hemşireler üzerinde yapmış olduğu çalışmada, iyi bir postüre sahip olmanın daha az kas-iskelet sistemi şikayetine sebep olduğu sonucu çalışmamızın bulgularıyla paralellik göstermektedir. Adams ve ark.'nın [7] jinekolojik cerrahlar üzerinde yapmış 
olduğu çalışmada ise doğru postürün kasiskelet sistemi ağrılarını azalttığı belirtilmektedir. Egzersiz süresinin/yılının artması belirgin bir şekilde şikayetlerinin azalması ile ilişkilidir. Bu nedenle cerrahların egzersize teşvik edilmesinin yanı sıra egzersiz alışkanlığına daha uzun yıllar devam etmelerinin sağlanmasının önemli olduğunu öngörüyoruz. Cerrahların çalışma saatlerinin iyileştirilip egzersizi yaşamlarının bir parçası haline getirebilmeleri hem kendileri hem de hastaları açısından önem arz etmektedir. Bunun bir halk sağlığı sorunu olarak ele alınıp cerrahların ve tabi ki toplumun diğer bireylerinin hayatları boyunca sporla iç içe yaşamalarının sağlanması gerekmektedir. Böylece Avrupa'daki en sık meslek hastalığı olarak gösterilmiş olan kas-iskelet sistemi ağrıları azalarak sağlık hizmetlerine başvuru ihtiyacının sıklığı düşecektir [2].

Çalışmanın tek merkezde yürütülmesi, nispeten genç yaştaki cerrahların çalışmaya katılması, cerrahların çalıştıkları kliniklere ve sıklıkla kullandıkları cerrahi tekniklere göre alt gruplara ayrılarak sınıflandırma yapılmaması bu çalışmanın kısıtlılıkları arasında sayılabilmektedir.

$\mathrm{Bu}$ çalışmanın sonucu olarak cerrahların düzenli egzersiz yapmaya teşvik edilmesini savunmaktayız. Böylece, doğru postür ve düşük VKI ile birlikte cerrahların kas-iskelet sistemi ağrısı şikayetlerinin azalacağını öngörmekteyiz. Ayrıca ergonomik eğitimlerin cerrahi eğitimin bir parçası olarak kabul görmesini ve cerrahi yetkinlik alan tüm bireylerin ergonomik bilincinin tam olması gerektiğini düşünmekteyiz.

Çıkar ilişkisi: Yazarlar çıkar ilişkisi olmadığını beyan eder.

\section{Kaynaklar}

1. Dalager T, Højmark A, Jensen PT, Søgaard K, Andersen LN. Using an intervention mapping approach to develop prevention and rehabilitation strategies for musculoskeletal pain among surgeons. BMC Public Health 2019;19:320. https://doi.org/10.1186/s12889019-6625-4

2. Dalager T, Søgaard K, Bech KT, Mogensen O, Jensen PT. Musculoskeletal pain among surgeons performing minimally invasive surgery: a systematic review. Surg Endosc 2017;31:516-526. https://doi.org/10.1007/ s00464-016-5020-9
3. Dalager T, Søgaard K, Boyle E, Jensen PT, Mogensen $O$. Surgery is physically demanding and associated with multisite musculoskeletal pain: a cross-sectional study. J Surg Res 2019;240:30-39. https://doi.org/10.1016/j. jss.2019.02.048

4. Knudsen ML, Ludewig PM, Braman JP. Musculoskeletal pain in resident orthopaedic surgeons: results of a novel survey. lowa Orthop J 2014;34:190-196.

5. Ruitenburg M, Frings Dresen M, Sluiter J. Physical job demands and related health complaints among surgeons. Int Arch Occup Environ Health 2013;86:271279. https://doi.org/10.1007/s00420-012-0763-7

6. Wells AC, Kjellman M, Harper SJ, Forsman M, Hallbeck MS. Operating hurts: a study of EAES surgeons. Surg Endosc 2019;33:933-940. https://doi.org/10.1007/ s00464-018-6574-5

7. Adams SR, Hacker MR, McKinney JL, Elkadry EA, Rosenblatt PL. Musculoskeletal pain in gynecologic surgeons. J Minim Invasive Gynecol 2013;20:656-660. https://doi.org/10.1016/j.jmig.2013.04.013

8. Hotton M, Miller R, Chan J. Performance anxiety among surgeons. The Bulletin of the Royal College of Surgeons of England 2019;101:20-26. https://doi. org/10.1308/rcsbull.2019.20

9. Radunz S, Hoyer DP, Kaiser GM, Paul A, Schulze M. Career intentions of female surgeons in German liver transplant centers considering family and lifestyle priorities. Langenbecks Arch Surg 2017;402:143-148. https://doi.org/10.1007/s00423-016-1434-z

10. Asghari E, Dianat I, Abdollahzadeh F, et al. Musculoskeletal pain in operating room nurses: associations with quality of work life, working posture, socio-demographic and job characteristics. Int J Ind Ergon 2019;72:330-337. https://doi.org/10.1016/j. ergon.2019.06.009

11. Öncü J, llişer R, Kuran B. Cross-cultural adaptation of the Orebro Musculoskeletal Pain Questionnaire among Turkish workers with low back pain. J Back Musculoskeletal Rehabil 2016;29:135-143. https://doi. org/10.3233/BMR-150609

12. Orthopedic physical assessment. Available at: https:// www.clinicalkey.com/dura/browse/bookChapter/3s2.0-C20100689619. Accessed August 15, 2021

13. Abd Rahman MN, RANI MRA, Rohani JM. WERA: an observational tool develop to investigate the physical risk factor associated with WMSDs. J Hum Ergol 2011;40:19-36. https://doi.org/10.11183/JHE.40.19

14. Catanzarite T, Tan Kim J, Whitcomb EL, Menefee S. Ergonomics in surgery: a review. Female Pelvic Med Reconstr Surg 2018;24:1-12. https://doi.org/10.1097/ SPV.0000000000000456

15. Meltzer AJ, Hallbeck MS, Morrow MM, et al. Measuring ergonomic risk in operating surgeons by using wearable technology. JAMA Surg 2020;155:444-446. https://doi. org/10.1001/jamasurg.2019.6384 
16. Foright $R$, Presby D, Sherk V, et al. Is regular exercise an effective strategy for weight loss maintenance? Physiol Behav 2018;188:86-93. https://doi.org/10.1016/j. physbeh.2018.01.025

17. Pandey A, LaMonte M, Klein L, et al. Relationship between physical activity, body mass index, and risk of heart failure. J Am Coll Cardiol 2017;69:1129-1142. https://doi.org/10.1016/j.jacc.2016.11.081

18. Swift DL, McGee JE, Earnest CP, Carlisle E, Nygard M, Johannsen NM. The effects of exercise and physical activity on weight loss and maintenance. Prog Cardiovasc Dis 2018;61:206-213. https://doi. org/10.1016/j.pcad.2018.07.014

19. Booth J, Moseley GL, Schiltenwolf M, Cashin A, Davies $M$, Hübscher M. Exercise for chronic musculoskeletal pain: a biopsychosocial approach. Musculoskeletal Care 2017;15:413-421. https://doi.org/10.1002/ msc. 1191

20. Jakobsen MD, Sundstrup E, Brandt M, Jay K, Aagaard P, Andersen LL. Effect of workplace-versus home-based physical exercise on musculoskeletal pain among healthcare workers: a cluster randomized controlled trial. Scand J Work Environ Health 2015;41:153-163. https://doi.org/10.5271/sjweh.3479

21. Kim D, Cho M, Park Y, Yang Y. Effect of an exercise program for posture correction on musculoskeletal pain. J Phys Ther Sci 2015;27:1791-1794. https://doi. org/10.1589/jpts.27.1791

22. Molina Garcia P, Mora Gonzalez J, Migueles $\mathrm{JH}$, et al. Effects of Exercise on Body Posture, Functional Movement, and Physical Fitness in Children With Overweight/Obesity. J Strength Cond Res 2020;34:2146-2155. https://doi.org/10.1519/ JSC.0000000000003655

23. Vranešić Hadžimehmedović D, Bajramović I, Likić S, Tabaković M, Imamović D. Effects of four-month exercise program on correction of body posture of persons with different visual impairment. J Anthr Sport Phys Educ 2018;2:15-18. https://doi.org/10.26773/ jaspe. 180403

Etik kurul onayı: Çalışmamız, Süleyman Demirel Üniversitesi Tıp Fakültesi Klinik Araştırmalar Etik Kurulu Başkanlığı tarafından 07.01.2020 tarihinde 21/301 sayılı karar ile onaylanmıştır.

\section{Yazarların makaleye olan katkıları}

S.A.Ö. ve S.E. çalışmanın ana fikrini ve hipotezini kurgulamışlardır. C.Ç., S.A.Ö. ve S.E. teoriyi geliştirmiş ve gereç yöntem bölümünü düzenlemişlerdir. Sonuçlar kısmınındaki verilerin toplanması ve değerlendirmesini H.T.A. ve E.A. yapmışlardır. Makalenin tartışma bölümü G.K. tarafından yazılmış, S.A.Ö. ve S.E. gözden geçirip gerekli düzeltmeleri yapmış ve onaylamıştır. Ayrıca tüm yazarlar çalışmanın tamamını tartışmış ve son halini onaylamıştır. 